\title{
O que dizem as avaliações de impacto das Unidades de Polícia Pacificadora (UPPs)?
}

Vinicius Felix da Silva ${ }^{1}$

\section{Introdução}

Em novembro de 2008, o Governo do Estado do Rio de Janeiro realizou na favela do Morro de Santa Marta, na cidade do Rio de Janeiro, a primeira incursão do que viria a ser conhecido como programa de Unidades de Polícia Pacificadora (UPPs), carro-chefe da política de segurança pública do governo Sérgio Cabral, do partido Movimento Democrático Brasileiro (MDB). Dois anos depois, em dezembro de 2010, a operação para "pacificação" dos complexos de favelas do Alemão e da Penha, transmitida pelos telejornais com ares de espetáculo, marca o momento em que as UPPs ganham maior notoriedade, inclusive internacional, e o início da participação das Forças Armadas como parceiras no arranjo que poderia, sem embargo, ser caracterizado como uma política pública de pacificação. Uma política mais abrangente do que o programa estruturante de UPPs, da Secretaria de
Estado de Segurança do Rio de Janeiro (Seseg), por contemplar programas complementares dos governos estadual, municipal e federal ${ }^{2}$.

Ainda em 21 de janeiro de 2009, através do Decreto no 41.650, o Governo Estadual do Rio de Janeiro cria formalmente a Unidade de Polícia Pacificadora ${ }^{3}$. Esse decreto não vai além de conceituar a UPP como um destacamento especializado da Polícia Militar do Estado do Rio de Janeiro (PMERJ) com atuação nas favelas da capital do estado - ou "uma tropa especializada e tecnicamente preparada e adaptada para a execução de açóes especiais concernentes à pacificação e manutenção da ordem pública nas comunidades carentes" (RIO DE JANEIRO, 2009). Apenas com o Decreto no 42.787, de 6 de janeiro de 2011, o programa de UPPs passa a contar efetivamente com uma normatização explicitando o que se poderia entender como a "doutrina" da política de pacificação. Além dos critérios de elegibilidade das áreas passíveis de intervenção

1 Mestrando no Programa de Pós-Graduaçáo em Ciências Humanas e Sociais da Universidade Federal do ABC (UFABC). E-mail: v.felix@ufabc.edu.br

2 Como o Programa UPP Social, originalmente desenhado pela Secretaria de Estado de Assistência Social e Direitos Humanos (SEASDH), mas posteriormente assumido pelo Instituto Pereira Passos (IPP), da Prefeitura Municipal do Rio de Janeiro; a aplicação estadual do Programa Territórios da Paz, preconizado pelo Governo Federal no âmbito do Programa Nacional de Segurança Pública com Cidadania (Pronasci); ou mesmo os investimentos de Urbanização de Assentamentos Precários do Plano de Aceleração do Crescimento (PAC-UAP), os mais notórios aplicados no Complexo do Alemão.

3 Nesse momento de mera formalização da situação iniciada no final do ano anterior, a Unidade de Polícia Pacificadora é referida no singular. 
e dos objetivos gerais traçados para o programa de UPPs ${ }^{4}$, um dos principais avanços do decreto na descrição do programa refere-se à enumeração das etapas que caracterizaram as intervençôes de pacificação $0^{5}$.

Considerando esses pontos, podemos dizer que o governo fluminense aponta como propósitos da política de pacificação, em primeiro lugar, desarticular a dominação privada sobre territórios e populaçôes marginalizadas da capital do Rio de Janeiro - e, posteriormente, de outras localidades da Baixada Fluminense -, exercida por grupos fora da lei fortemente armados. E, em segundo lugar, estabelecer um aparato permanente de policiamento de proximidade que assegure condiçôes mínimas de segurança para a ampliação da rede de serviços públicos e privados disponíveis para os territórios e populaçóes objeto da pacificação - a partir de entáo classificadas como "comunidades pacificadas" -, o que, por sua vez, diminuiria a "distância" social dessas em relação às do restante da cidade formal, no que diz respeito ao exercício dos direitos de cidadania e ao desenvolvimento econômico e social. Parte-se, assim, do reconhecimento da existência de lacunas territoriais no monopólio estatal da violência legitima, para então afirmar a (re)instauração desse monopólio, por meios extraordinários, como condição sine qua non para o "exercício da cidadania plena”.

Passados nove anos de implantação, a política de pacificação parece ter chegado ao seu ponto de exaustão e se direcionar para a completa dissoluçáo, dentro do quadro geral de grave crise fiscal e de legitimidade política pelo qual passa o Governo do Estado do Rio de Janeiro, cujo simbolismo maior foi a renúncia do responsável pela implementação do programa de UPPs, José Mariano Beltrame, pouco após a troca de gestão do governo, em 2014. Mesmo diante desse quadro, ainda não é possível identificar qualquer consenso nos

4 "Art. 10 As Unidades de Polícia Pacificadora (UPP), criadas para a execução de ações especiais concernentes à pacificação e à preservação da ordem pública, destinam-se a aplicar a filosofia de polícia de proximidade nas áreas designadas para sua atuação.

$\$ 1$ Sáo áreas potencialmente contempláveis por UPP, consoante critérios estabelecidos pela Secretaria de Estado de Segurança, aquelas compreendidas por comunidades pobres, com baixa institucionalidade e alto grau de informalidade, em que a instalação oportunista de grupos criminosos ostensivamente armados afronta o Estado Democrático de Direito.

$\$$ 2o São objetivos das UPP: a) consolidar o controle estatal sobre comunidades sob forte influência da criminalidade ostensivamente armada; b) devolver à população local a paz e a tranquilidade públicas necessárias ao exercício da cidadania plena que garanta o desenvolvimento tanto social quanto econômico.” [RIO DE JANEIRO, Governo do Estado, 2011]

5 "Art. 2० O programa de pacificação, por meio da implantação de UPP, deverá ser realizado nessas comunidades em quatro etapas: I - INTERVENÇÃO TÁTICA - Primeira etapa, em que são deflagradas açōes táticas, preferencialmente pelo Batalhão de Operaçóes Policiais Especiais (BOPE), pelo Batalhão de Polícia de Choque (BPChoque) e por efetivos deslocados dos CPA, com o objetivo de recuperarem o controle estatal sobre áreas ilegalmente subjugadas por grupos criminosos ostensivamente armados. II - ESTABILIZAÇÃO - Momento em que são intercaladas ações de intervenção tática e açôes de cerco da área delimitada, antecedendo o momento de implementação da futura UPP. III - IMPLANTAÇÃO DA UPP - Ocorre quando policiais militares especialmente capacitados para o exercício da polícia de proximidade chegam definitivamente à comunidade contemplada pelo programa de pacificação, preparando-a para a chegada de outros serviços públicos e privados que possibilitem sua reintegração à sociedade democrática. Para tanto, a UPP contará com efetivo e condiçóes de trabalho necessários ao adequado cumprimento de sua missão. IV - AVALIAÇÃO E MONITORAMENTO - Nesse momento, tanto as açóes de polícia pacificadora, quanto as de outros atores prestadores de serviços públicos e privados nas comunidades contempladas com UPP passam a ser avaliados sistematicamente com foco nos objetivos, sempre no intuito do aprimoramento do programa." [RIO DE JANEIRO, Governo do Estado, 2011] 
debates públicos e acadêmicos acerca de um sentido inequívoco a ser atribuído à política de pacificação. Não é arriscado afirmar que a normatização tardia das UPPs contribuiu para esse acúmulo de incertezas e ambiguidades. Diante de um vácuo normativo de mais de dois anos, é completamente especulativo supor que o programa tenha obedecido homogeneamente as mesmas diretrizes antes ou mesmo depois de 2011. De toda forma, o Decreto $\mathrm{n}^{\circ} 42.787 / 2011$ constitui a principal fonte formal para se discorrer sobre o que essa política deveria e poderia ser e, portanto, para avaliar seus resultados legítimos e ilegítimos, ou mesmo legais e ilegais, como a própria ausência de norma suscita, bem como para se elaborar sobre quais são os seus legados, quais foram as oportunidades perdidas e quais potencialidades e riscos persistem mesmo diante da iminência de descontinuação da política.

Se o significado de "pacificação" como propósito de política pública ainda constitui um enigma, de uma forma um tanto paradoxal, a investigaçáo empírica dos impactos sociais concretos das UPPs se apresenta como uma estratégia pragmática para se aproximar de sua solução. O presente artigo explora essa frente, identificando as contribuiçôes do estado da arte dos estudos nacionais e internacionais de avaliação de impacto das Unidades de Polícia Pacificadora para a compreensão da política de pacificação do Rio de Janeiro, propondo uma síntese de seus principais resultados e achados a partir da ótica de suas consequências para o exercício de direitos de cidadania nas comunidades pacificadas.

A principal contribuição deste trabalho é propor o uso de uma metodologia essencialmente qualitativa, a de revisão sistemática (DE-LA-TORRE-UGARTE-GUANILO; TAKAHASHI; BERTOLOZZI, 2011; BOTELHO; CUNHA; MACEDO, 2011) ou estudo de estado da arte (FERREIRA, 2002), como estratégia de abordagem indireta a dados quantitativos sobre um determinado fenômeno de política pública. Desta forma, a pesquisa explora um ponto comum a um conjunto de estudos - a abordagem de avaliaçáo de impactos de políticas públicas -, como pivô para se mobilizar o conhecimento já acumulado sobre o programa de Unidades de Polícia Pacificadora do Rio de Janeiro.

$\mathrm{O}$ artigo está organizado em oito partes, contando esta introduçáo. A primeira seçấo apresenta os procedimentos adotados para a seleçâo da amostra de literatura revisada como representativa do estado da arte da avaliaçâo de impactos das UPPs. A segunda seção insere a discussão sobre as UPPs no contexto da avaliação de impactos de políticas públicas. A terceira seção trata das principais contribuiçóes dos estudos revistos quanto à caracterização do programa de UPPs. A quarta seção apresenta a discussão sobre os critérios de seleção da localização das UPPs, e a quinta seção expóe seus principais impactos em dimensóes criminais; enquanto a sexta seção, trata dos impactos em dimensóes não criminais. À guisa de consideraçôes finais, apresenta-se, além da síntese dos resultados e suas lacunas, sugestóes para pesquisas subsequentes.

\section{Metodologia: revisão sistemática do estado da arte}

Segundo Ferreira (2002, p. 2, grifo meu), as pesquisas de "estado da arte" são definidas

como de caráter bibliográfico, [tendo] em comum o desafio de mapear e de discutir uma certa produção acadêmica em diferentes campos do conhecimento, tentando responder que aspectos e dimensōes vêm sendo destacados e privilegiados em diferentes épocas e lugares [...]. Também são reconhecidas por realizarem uma metodologia de caráter inventariante e descritivo da produção acadêmica e científica sobre o tema que busca investigar, à luz de categorias e facetas que se caracterizam enquanto tais em cada trabalho e no conjunto deles, sob os quais o fenômeno passa a ser analisado. 
Esse tipo de pesquisa toma a própria literatura acadêmica como fenômeno de análise, evidenciando aspectos quantitativos e qualitativos de sua produção, armazenamento, difusão e/ou diálogo intertextual. Além de procedimentos de levantamento, categorizaçáo e inventariação de diferentes produtos acadêmicos, pode-se aplicar também procedimentos sistemáticos de leitura, comparação, sintese e apresentaçâo dos conteúdos de obras selecionadas, os quais permitem, por sua vez, caracterizar a pesquisa como uma revisão sistemática (DE-LA-TORRE-UGARTE-GUANILO; TAKAHASHI; BERTOLOZZI, 2011; BOTELHO; CUNHA; MACEDO, 2011), que distingue-se da revisão bibliográfica tradicional por ativamente visar diminuir o viés do pesquisador na seleção do material revisado. Dentro do "guarda-chuva" mais geral da revisão sistemática, optei pela metodologia da revisáo integrativa, que, segundo Botelho, Cunha e Macedo (2011, p. 127), "possibilita a síntese de vários estudos já publicados, permitindo a geração de novos conhecimentos, pautados nos resultados apresentados pelas pesquisas anteriores".

O levantamento de referências para revisão foi feito através de consultas com palavras-chave em search engines de bancos de dados on-line. $\mathrm{O}$ primeiro resultado observado no levantamento de referências sobre a política de pacificação do Rio de Janeiro e o programa de UPPs é a própria profusão de documentos disponibilizados on-line tratando sobre essa política, o que, por si só, obriga o pesquisador a descartar de pronto qualquer pretensão de revisão exaustiva sobre o tema. Além da produção acadêmica propriamente dita, o universo em questão contempla uma miríade de notícias, postagens de blogs e documentos (semi) oficiais.

Além desse levantamento inicial através do Google, feito apenas para se ter uma dimensão da quantidade bruta de materiais sobre as UPPs, os bancos de fontes acadêmicas consultados foram: Google Academics (ou Google Scholar), SciELO, Periódicos Capes, Capes Teses e Biblioteca Digital Brasileira de Teses e Dissertaçóes (BDTD). Como horizonte temporal, considerou-se os resultados referentes a um período de mais de dez anos, entre $1^{\circ} \mathrm{de}$ janeiro de 2006 e 30 de setembro de 2016, quando o levantamento foi realizado.

As buscas ainda foram ajustadas para trazer resultados em língua portuguesa e inglesa, conforme a língua adotada para elaboração das sintaxes de busca. A estratégia adotada para refinar os resultados foi a aplicação de treads de busca sucessivamente mais restritivas - isto é, partindo-se da sintaxe mais aberta, [Pacificação + "Rio de Janeiro"], para as mais restritivas, ["polícia pacificadora" + "avaliação de impacto" (ou, alternativamente, "avaliação do impacto") - "impacto ambiental”] ] -, redundando em uma pré-seleção de 53 resultados, correspondentes às células destacadas nos Quadros 1 e 2, que demonstram os resultados de buscas, respectivamente, em língua portuguesa e inglesa.

Esses 53 resultados iniciais foram então submetidos à avaliação de seus títulos, abstracts e conteúdos textuais, quanto à sua pertinência ao assunto investigado - avaliação de impacto das unidades de polícia pacificadora. Critérios de inclusão e exclusão (de caráter eliminatório), descritos no Quadro 3, foram adotados visando evitar a contagem de "falsos positivos".

6 Adotou-se a subtração da expressão "impacto ambiental” como condição da busca para eliminar resultados que apontavam para "Relatórios de Avaliação de Impacto Ambiental", documento formalmente exigido por legislação específica para a realização de obras, uma vez que isso foge da discussão dessa pesquisa. 


\section{Quadro 1}

Resultados em português de buscas por palavras-chave em search engines $(1 / 1 / 06$ - 30/9/16)

\begin{tabular}{|c|c|c|c|c|c|c|}
\hline & Google & $\begin{array}{c}\text { Google Academics } \\
(\mathbf{2 0 0 6 - 2 0 1 6 )}\end{array}$ & SciELO & $\begin{array}{c}\text { Periódicos } \\
\text { Capes }\end{array}$ & $\begin{array}{c}\text { Capes } \\
\text { Teses }\end{array}$ & BDTD \\
\hline "UPP" + "Rio de Janeiro" & $191.000+$ & $2.160+$ & 4 & 36 & & 25 \\
\hline pacificação + "Rio de Janeiro" & 88.500 & $15.900+$ & 3 & 16 & & 22 \\
\hline "policiamento de pacificação" & 6 & 1 & 0 & 0 & & 0 \\
\hline $\begin{array}{c}\text { "polícia pacificadora" } \\
\text { "polícia pacificadora" + impacto } \\
\text {-"impacto ambiental" }\end{array}$ & $5.180+$ & $1.040+$ & 0 & 5 & & 23 \\
\hline $\begin{array}{c}\text { "polícia pacificadora" + avaliação } \\
\text {-"impacto ambiental" }\end{array}$ & $8.230+$ & 988 & 0 & 5 & & 4 \\
\hline $\begin{array}{c}\text { "polícia pacificadora" + impacto + } \\
\text { avaliação - "impacto ambiental" }\end{array}$ & $2.700+$ & 766 & 0 & - & & 3 \\
\hline $\begin{array}{c}\text { "policia pacificadora" + "avaliação de } \\
\text { impacto" - "impacto ambiental" }\end{array}$ & 39 & 17 & 0 & 0 & & 2 \\
\hline $\begin{array}{c}\text { "policia pacificadora" + "avaliação do } \\
\text { impacto" - "impacto ambiental" }\end{array}$ & 43 & 23 & 0 & 0 & & 0 \\
\hline
\end{tabular}

Fonte: Elaboração própria

\section{Quadro 2}

Resultados em inglês de buscas por palavras-chave em search engines $(1 / 1 / 06$ - 30/9/16)

\begin{tabular}{|c|c|c|c|c|c|c|}
\hline & Google & $\begin{array}{l}\text { Google Academics } \\
(2006-2016)\end{array}$ & SciELO & $\begin{array}{l}\text { Periódicos } \\
\text { Capes }\end{array}$ & $\begin{array}{l}\text { Capes } \\
\text { Teses }\end{array}$ & BDTI \\
\hline "UPP" + "Rio de Janeiro" & $191.000_{+}$ & 809 & - & 28 & & 1 \\
\hline pacification + "Rio de Janeiro" & $11.100+$ & $1.790+$ & 5 & 50 & & 0 \\
\hline "pacification police" & 809 & 120 & & 161 & 5 & 0 \\
\hline $\begin{array}{l}\text { "pacification police" + impact } \\
\text {-"environmental impact" }\end{array}$ & 351 & 107 & 0 & 0 & & - \\
\hline $\begin{array}{l}\text { "pacification police" + evaluation } \\
\text {-"environmental impact" }\end{array}$ & 87 & 49 & 0 & 0 & & - \\
\hline $\begin{array}{c}\text { "pacification police" + impact + } \\
\text { evaluation - "environmental impact" }\end{array}$ & 46 & 47 & 0 & 0 & & - \\
\hline $\begin{array}{c}\text { "pacification police" + "impact } \\
\text { evaluation" - "environmental impact" }\end{array}$ & 5 & 1 & 0 & 0 & & - \\
\hline "pacifying police" & $3.850+$ & 330 & & 59 & 40 & 1 \\
\hline $\begin{array}{l}\text { "pacifying police" + impact } \\
\text {-"environmental impact" }\end{array}$ & $1.240+$ & 287 & & 2 & & 0 \\
\hline $\begin{array}{l}\text { "pacifying police" + evaluation } \\
\text {-"environmental impact" }\end{array}$ & 345 & 156 & & 1 & & 0 \\
\hline $\begin{array}{c}\text { "pacifying police" + impact + } \\
\text { evaluation - "environmental impact" }\end{array}$ & 208 & 150 & & 1 & & - \\
\hline $\begin{array}{c}\text { "pacifying police" + "impact } \\
\text { evaluation" - "environmental impact" }\end{array}$ & 13 & 10 & & 0 & & - \\
\hline
\end{tabular}

Fonte: Elaboração própria 
Quadro 3

Critérios de seleção dos documentos

\begin{tabular}{|c|c|}
\hline Critérios de Inclusão & Critérios de Exclusáo \\
\hline $\begin{array}{l}\text { - Apresenta indicadores de impacto da política de } \\
\text { pacificaçấo em comunidades pacificadas. } \\
\text { - Apresenta indicadores de impacto da política de } \\
\text { pacificação do Rio de Janeiro. } \\
\text { - Apresenta indicadores sociais referentes às } \\
\text { comunidades pacificadas. } \\
\text { - Sugere metodologia para avaliaçấo de impacto da } \\
\text { política de pacificação do Rio de Janeiro. }\end{array}$ & $\begin{array}{l}\text { - Não trata da política de pacificaçáo da cidade do Rio } \\
\text { de Janeiro. } \\
\text { - Não aborda avaliação de impacto. } \\
\text { - Referência pontual ao tema (até duas citaçóes das } \\
\text { palavras-chave). } \\
\text { - Duplicata da discussáo. } \\
\text { - Duplicata do documento. } \\
\text { - Documento final inacessível. }\end{array}$ \\
\hline
\end{tabular}

Fonte: Elaboração própria.

Os quatro critérios de inclusão remetem a aspectos propriamente materiais. $\mathrm{O}$ enquadramento mais estrito se refere à presença de indicadores de impacto das UPPs em comunidades pacificadas, enquanto o mais abrangente se refere à simples presença de proposta metodológica para avaliação de impactos da política de pacificação. Três critérios materiais de exclusão enquadraram os resultados que, apesar de identificados pelos procedimentos de busca, em seus conteúdos não tratavam de fato da avaliação de impactos de políticas públicas, abordando esse tema apenas pontualmente ${ }^{7}$; ou evocavam equivocadamente a avaliação de impactos, sem efetivamente observarem as premissas dessa abordagem, conforme discuto na próxima seção. Os três critérios restantes formais de exclusão se referiam a resultados que duplicavam, sob outro título, a mesma discussão; a resultados duplicados, i.e., referentes a um mesmo documento disponibilizado em mais de um link dos sistemas de busca ${ }^{8}$; e a links "quebrados", que não possibilitavam o efetivo acesso ao documento final.

Com a eliminação desses e outros resultados "falsos positivos", foi possível chegar a uma amostra de doze documentos, que formaram a amostra efetivamente revisada neste artigo", sumarizada, quanto a composição por língua e ano de publicação, nos Quadros 4 e 5.

Além desses doze documentos, optou-se por excepcionalmente incluir um artigo que não fora identificado diretamente nos levantamentos nos search engines: "Crime, house prices and inequality: the effect of UPP in Rio", de Claudio Frischtak e Benjamin Mandel, publicado em janeiro de 2012 artigo referido quase consensualmente como um trabalho seminal na avaliação de impactos das UPPs, ao lado do trabalho de Ignácio Cano, Doriam Borges e Eduardo Ribeiro,

7 Um método utilizado para localizar preliminarmente esses casos foi o uso da busca da palavra-chave "avaliaçấo de impacto" e algumas de suas variantes, focalizando como problemáticos aqueles que resultavam em no máximo duas citaçôes. Todos esses documentos, no entanto, foram submetidos a leitura mais detida para se evitar a classificação de "falsos negativos".

8 P.ex., os resultados duplicados por conta das traduçóes de títulos e resumos para a língua inglesa, exigência comum para a publicaçáo em periódicos científicos.

9 Como muitos resultados se enquadraram em mais de um critério de inclusão e/ou exclusão, optou-se por năo apresentar a sua quantificação precisa, o que mais atrapalharia do que ajudaria a esclarecer como se chegou a essa amostra final. 
Os donos do morro: uma avaliação exploratória do impacto das Unidades de Polícia Pacificadora (UPPS) no Rio de Janeiro, que veio a público alguns meses depois, em maio de 2012, este sim identificado pela metodologia para levantamento da amostra de literatura. Os estudos subsequentes dialogam direta e explicitamente com ambos os trabalhos, como referências que estabeleceram muitos dos critérios conceituais e metodológicos seguidos desde o ano divisor de águas de 2012, e cuja leitura, portanto, se fazia essencial para a plena compreensão desse corpo de literatura. Por essa razão, mesmo configurando uma opção heterodoxa em relação à metodologia adotada para o levantamento de literatura, pareceu-me injusto abordar apenas o trabalho de Cano, Borges e Ribeiro (2012) e relegar a segundo plano o trabalho de Frischtak e Mandel (2012), publicado não apenas antes, mas já elaborado tendo em vista um público internacional. Neste sentido, o texto também serviu como um complemento para a representatividade dos estudos de avaliação de impacto das UPPs em língua inglesa, que de outra forma se limitaria a um único documento aprovado na triagem.

$\mathrm{Na}$ próxima seção, apresento algumas premissas que, além de contextualizar a discussão desenvolvida nos documentos arrolados como amostra representativa do estado da arte da avaliaçáo de impactos das UPPs, foram adotadas para sua categorizaçấo e efetiva análise de resultados.

\section{Quadro 4}

Documentos excluídos e incluídos, por língua

\begin{tabular}{|c|c|c|c|}
\hline & Inglês & Português & Total geral \\
\hline Excluídos & 10 & 31 & 41 \\
\hline Incluídos & 1 & 11 & 12 \\
\hline Total geral & 11 & 42 & 53 \\
\hline
\end{tabular}

Fonte: Elaboração própria

\section{Quadro 5}

Documentos incluídos, por língua e ano de publicação

\begin{tabular}{|c|c|c|c|c|c|c|}
\hline & $\mathbf{2 0 1 2}$ & $\mathbf{2 0 1 3}$ & $\mathbf{2 0 1 4}$ & $\mathbf{2 0 1 5}$ & $\mathbf{2 0 1 6}$ & Total geral \\
\hline Inglês & & & & 1 & & 1 \\
\hline Português & 2 & 4 & 2 & 2 & 1 & 11 \\
\hline Total geral & 2 & 4 & 2 & 3 & 1 & 12 \\
\hline
\end{tabular}

Fonte: Elaboração própria

\section{A avaliação de impacto de políticas públicas e as UPPs}

O objetivo deste artigo é contribuir para a investigação sobre a política de pacificação do Rio de Janeiro a partir de uma abordagem interpretativa dos estudos de avaliação de impacto das UPPs - representados, de maneira não exaustiva, pela amostra selecionada conforme os procedimentos apresentados na seção anterior -, por considerar essa literatura um dos principais filóes de investigação 
empírica sobre o tema ${ }^{10}$. É claro que isso não significa que tal literatura seja fonte de puras consideraçôes "técnicas" e "neutras". Não é necessário repisar toda a discussão sobre a impossibilidade de neutralidade objetiva nas ciências sociais, ou mesmo nas chamadas hard sciences, para se afirmar que toda e qualquer pesquisa de avaliação de política pública precisa partir de alguns pressupostos políticos sobre a formulação da política e seu contexto de implementação se pretende minimamente discriminar o que, afinal, estará avaliando. De forma que, apesar de terem como objetivo explícito identificar resultados não apriorísticos das UPPs, os estudos ora revisados precisaram explicitar, mesmo que a título de hipóteses, premissas mínimas acerca do programa de UPPs e da problemática social concreta frente à qual a política de pacificação é apresentada como uma solução. Assim, importantes insights sobre a política de pacificação e o programa de UPPs já transparecem nos impasses que os pesquisadores buscaram contornar com as metodologias de avaliação de impacto adotadas.

Preliminarmente, é necessário esclarecer que a relação entre segurança pública e política pública é controversa já a partir das distinçóes entre as políticas de segurança pública e as políticas públicas de segurança (FILOCRE, 2009). Pensada por qualquer desses vieses, a questão do papel da ação governamental sobre a problemática da (in)segurança na cidade do Rio de Janeiro dá azo para outras infinitas controvérsias sobre os propósitos, a legitimidade e a efetividade das diversas políticas de segurança pública, stricto sensu, isto é, referentes à aplicação das forças policiais, bem como de outras estratégias de políticas públicas de segurança. A própria política de pacificação se insere nesse tipo de dilema, pelo fato de mesmo o programa policial das UPPs ser explicitamente descrito como uma ação preparatória e complementar a outras intervençôes públicas e privadas de cunho "social".

Uma forma encontrada pelos pesquisadores para minimizar a ambiguidade aparentemente intencional em torno do significado de "pacificação", sem se contaminarem pelos julgamentos de valor a priori, foi a de tentarem compreendê-la antes pelos seus efeitos perceptíveis do que pelos propósitos (não) declarados pelas autoridades fluminenses. Assim, aplicaram pesquisas avaliativas sobre aquela política pública.

Como apontado por Cano, Borges e Ribeiro (2012, p. 11-13), já a partir de 2009 podemos observar a publicação de pesquisas avaliativas sobre a política de pacificação e o programa de UPPs. Apesar das limitaçóes metodológicas dessas primeiras avaliaçóes, como se basearem quase que exclusivamente em pesquisas de opiniáo e considerarem espaços amostrais pequenos e com pouca diversidade em termos das comunidades pacificadas estudadas - todos problemas, senáo decorrentes, agravados pelo fato de que, no momento de elaboraçáo dos primeiros protocolos de pesquisa, o programa contava com menos de dois anos de execução -, essas pesquisas já evidenciavam padróes que, anos mais tarde, seriam validados por pesquisas com dados mais robustos e análises mais sofisticadas - como a diminuição dos conflitos entre quadrilhas e dessas contra policiais; aumento da regularização de serviços públicos e privados; aumento da realização de obras e dos preços imobiliários; bem como a permanência de tensôes entre moradores e policiais e baixa expectativa quanto à continuidade do programa ou seus efeitos em médio e longo prazo.

10 Ao lado das pesquisas de opiniāo e etnografias realizadas nos cenários de implementação das Unidades de Polícia Pacificadora. 
$\mathrm{O}$ ano de 2012 representa uma inflexão nessa literatura, a partir da publicação dos trabalhos de Frischtak e Mandel (2012) e de Cano, Borges e Ribeiro (2012), que podemos apropriadamente classificar como avaliaçóes de impacto, isto é, pesquisas que visavam mensurar os efeitos específicos das intervençóes da política pública, destacando-os de mudanças meramente tendenciais na evoluçáo dos indicadores socioeconômicos do período considerado.

A avaliação de políticas públicas, em um sentido mais geral, é uma dimensão ou fase constitutiva do processo de política pública (RIPLEY, 1985) que, segundo Faria (2005, p. 97-98, grifos no original), pode ser definida como:

(a) atividade destinada a aquilatar os resultados de um curso de ação cujo ciclo de vida se encerra; (b) a fornecer elementos para o desenho de novas intervençōes ou para o aprimoramento de políticas e programas em curso; e (c) como parte da prestação de contas e da responsabilização dos agentes estatais, ou seja, como elemento central da accountability.

Para atender a esses propósitos, a avaliação de políticas públicas se operacionaliza como uma forma de pesquisa social aplicada, adotando métodos variados para identificar, classificar, analisar e sintetizar dados e informaçóes, visando inferências sobre a eficiência de açôes, instrumentos, equipes, projetos, programas e planos de governo concretamente produzidos no âmbito de políticas públicas. A avaliação não se realiza apenas nas fases finais de uma política, podendo investigar condiçóes antes, durante e depois da realização e finalização de determinadas intervençôes de políticas públicas ${ }^{11}$.

Avaliaçóes de políticas públicas são realizadas pelas agências governamentais diretamente interessadas, mas também por outros atores, como outras agências, empresas, organizaçóes da sociedade civil e também pela academia. Assim, além dos interesses pragmáticos relacionados ao controle do ciclo de vida de uma política pública, essas avaliaçôes, como qualquer outro empreendimento de pesquisa, são, ou pelo menos buscam ser, fontes de conhecimentos para o avanço nos campos científicos que tangem os fenômenos de intervenção da política pública.

Dentre as diversas ramificaçóes dos estudos de avaliação de políticas públicas, as avaliaçóes de impactos se notabilizam pelo ideal de se aproximar dos critérios de validação experimental das chamadas hard sciences, atingindo, se náo o nível do experimento puro, pelo menos aquele do quase-experimento ou, em melhores condições, o do experimento natural, a depender da própria natureza da intervenção estudada (RIBEIRO, 2013, p. 38-39).

Resumidamente, um estudo de avaliação de impactos busca identificar, mensurar e ponderar os resultados imediatos da execução das políticas públicas, ou outputs, relativamente aos impactos observáveis no ambiente natural e social de sua intervenção, ou outcomes (COHEN; FRANCO, 2008). O que implica ir alguns passos além da mensuração simples de variaçóes em estados do ambiente, através da proposição de modelos teóricos explicativos dos mecanismos de transmissão causal, que relacionem as mudanças em determinadas variáveis de interesse às intervençóes avaliadas, isolados os efeitos de outros fenômenos coincidentes sobre aqueles observados, permitindo, assim, a comparabilidade com resultados de outras intervençóes distantes no tempo ou no espaço. Considerando que as políticas

11 Situaçóes que podem ser encontradas na literatura referidas por termos técnicos como, respectivamente, "diagnóstico”, "monitoramento" e "avaliação" (propriamente dita). 
públicas são fenômenos sociais que podem ter impactos agudos em determinados processos sociais e naturais, as avaliaçóes de impacto de políticas públicas consistem em material valioso para a pesquisa nas ciências humanas e sociais, ao desnudarem relaçôes que podem ajudar a compreender, ou pelo menos identificar com maior confiabilidade o sentido e a intensidade de determinados processos, seja no sentido de ruptura ou de preservaçáo de regularidades identificáveis.

A complexidade da política de pacificação impóe desafios consideráveis para qualquer protocolo de pesquisa avaliativa, mesmo que essa não configure uma avaliaçáo de impacto. Um complicador evidente é a própria regulamentação tardia dos propósitos, diretrizes, objetivos e fases de intervenção das UPPs. A ausência de parâmetros normativos claros em relação aos quais a implementação concreta poderia ser referenciada e comparada torna meramente especulativa qualquer expectativa de homogeneidade temporal e espacial nas práticas implementadas nas UPPs, pelo menos entre novembro de 2008 e janeiro de 2011.

A esse fator se juntam outros, relacionados ao desenho da política de pacificação, como o fato de englobar um conjunto heterogêneo de programas e projetos de origem estadual, municipal, federal e mesmo privada associados às UPPs, o que náo apenas impóe que se considere a sobreposição de lógicas de intervenção (e, portanto, de avaliação) distintas. Incidem também fatores comuns às políticas de segurança pública de modo geral, como as questóes do sub-registro ou subnotificaçáo criminal, da migração criminal e dos mecanismos de transmissão dos efeitos esperados e observados, questóes que induzem a dilemas sobre como interpretar a efetividade das açóes policiais com base nas variações nos registros de ocorrências. Além disso, características próprias do contexto da pacificaçấo, como a heterogeneidade espacial e social dentro e entre as comunidades pacificadas e seus entornos $\mathrm{e}$ o fato de que as intervençôes das UPPs ocorreram em momentos diferentes - e que essas diferenças temporais implicaram variaçóes consideráveis em procedimentos e grau de maturidade institucional das agências responsáveis pela sua implementação - representam desafios não corriqueiros para a interpretação dos dados.

Por outro lado, essa mesma variedade de contextos representa oportunidade valiosa para a aplicação de metodologias mais sofisticadas de avaliação de impactos de políticas públicas. Segundo Ribeiro (2013, p. 39-40; grifos no original):

\begin{abstract}
A instalaçáo de uma UPP consiste em um evento bem localizado no tempo e no espaço, a partir do qual ocorre, ou espera-se que ocorra, uma alteração abrupta na evolução e no comportamento de determinados fenômenos, mudando o nível ou a tendência de séries históricas. Este efeito remete ao que economistas denominam choques. Por conta da redução que operam nos níveis de vitimização as UPPs devem alterar drasticamente um conjunto amplo de variáveis sociais, possibilitando explorar justamente as associaçóes que existiam entre estas variáveis e a violência.

Por outro lado, o fato desta redução na violência náo ser ampla, mas pontual, no sentido de que abrange apenas as [...] áreas das UPPs, possibilita estabelecer grupos de comparaçấo, passíveis de serem utilizados para avaliar em paralelo a evolução de determinados fenômenos de interesse no mesmo período, em localidades com e sem a intervenção. Esta possibilidade remete metodologicamente à noçáo de experimento natural, na medida em que a própria forma como é executada a política permite um maior controle da situaçáo experimental, do contexto em que é realizada a pesquisa.
\end{abstract}

Isto é, com uma metodologia adequada é possível transformar uma miríade de fatores que, inicialmente, representam desafios para a análise em parâmetros de comparação que facilitem a observação controlada de cadeias causais mais delimitadas. 
Nesse sentido, os estudos ${ }^{12}$ de avaliação de impacto ora selecionados confluem, quase que em sua totalidade, para a adoção do método de estimação de diferenças-em-diferenças (DD) como instrumento para efetuar a avaliação de impacto, metodologia oriunda da econometria, aplicável a situaçôes quase-experimentais ou de experimentos naturais, isto é, em relação a fenômenos não passíveis de controle direto pelo pesquisador, precisamente como costuma ocorrer na análise de políticas públicas. Segundo Butelli (2015, p. 184):

\begin{abstract}
Para analisar um experimento natural é preciso ter um grupo de controle, isto é, um grupo que não foi afetado pela mudança, e um grupo de tratamento, que foi afetado pelo evento, ambos com características semelhantes. Para estudar as diferenças entre dois grupos são necessários dados de antes e de depois do grupo do evento para ambos. Assim, a amostra está dividida em quatro grupos: o grupo de controle de antes da mudança, o grupo de controle depois da mudança, o grupo de tratamento antes da mudança, e o grupo de tratamento depois da mudança. A disparidade entre a diferença verificada entre os dois períodos e entre cada um dos grupos é a diferença-em-diferença.
\end{abstract}

A depender do desenho experimental, essas premissas são articuladas em modelos de testes estatísticos mais ou menos complexos, visando distinguir e isolar aquelas variaçôes "significativas" o bastante para serem reputadas como consequências específicas do "tratamento" (i.e., da política pública) daquelas cujas alteraçóes podem ser explicadas por mero comportamento tendencial, proporcionais, portanto, em ambos os grupos, controle e tratamento, durante o experimento. Esse ponto em comum, ao mesmo tempo em que confere uma base de comparação entre os diferentes estudos, também ajuda a explicar as diferenças nos resultados encontrados: as escolhas relativas, principalmente, a fonte e tratamento dos dados brutos, agregação geográfica, categorização, intervalo temporal, comunidades analisadas e referência para grupo de controle, levam, naturalmente, a resultados não inteiramente comensuráveis, sem que isso possa ser tomado, levianamente, como indicativo de diferença na robustez das modelagens propostas em cada estudo. Náo por acaso, as diferenças nesses resultados são antes de grandeza do que de sentido dos impactos, o que nos permite inferir conclusôes gerais das tendências evidenciadas pelo conjunto dos estudos, matizadas pelas contribuiçóes idiossincráticas de cada um deles.

Dentre os estudos revisados, as exceçóes no uso do método de estimaçáo de diferença-em-diferença foram: Ribeiro (2013), que utilizou o método de séries temporais múltiplas (STM), similar à lógica do método DD, no que compara as diferenças entre grupos de teste e controle antes e depois de um determinado "tratamento", mas adotando a passagem gradual de tempo como um fator crucial de mensuração; e Misse (2014) e Sá (2013), que fizeram mensuraçóes simples da diferença entre os dados observados após a instalação das UPPs e os valores que seriam esperados com a simples extrapolaçấo tendencial dos valores observados antes da instalação das UPPs.

Considerando-se os objetivos da política de pacificaçáo explicitados no Decreto ${ }^{\circ}$ $42.787 / 2011$ - por um lado, "consolidar o controle estatal sobre comunidades sob forte influência da criminalidade ostensivamente armada" e, por outro lado, "devolver à população

12 Optei por me referir antes a "estudos" do que a "trabalhos" como objetos dessa revisão pelo fato de que algumas das publicaçóes revisadas traziam, de fato, mais de um estudo avaliativo sobre a política de pacificação, com distintas fontes de dados, metodologias, abordagens e período de publicação. 
local a paz e a tranquilidade públicas necessárias ao exercício da cidadania plena que garanta o desenvolvimento tanto social quanto econômico"-, os estudos analisados foram categorizados esquematicamente em dois grandes grupos.

O primeiro grupo engloba os estudos concentrados em dimensões diretamente relacionadas à atividade policial, à criminalidade e à violência, e que permitem inferências sobre o sucesso na retomada do controle territorial estatal e suas consequências sobre o gozo de liberdades individuais (p. ex., direito à vida, à integridade física e moral, de ir e vir, de expressão e informação, de acesso à Justiça, aos registros e cadastros civis) dentro e fora das comunidades pacificadas. Os estudos categorizados nesse primeiro grupo podem ser subdivididos em três subgrupos, com base nas variáveis dependentes consideradas:

1. Registros oficiais de atividade policial, através dos Talóes de Registro de Ocorrência (TROs), preenchidos pelos policiais em serviço: Cano, Borges e Ribeiro (2012), particularmente o Capítulo 9; Ferraz e Ottoni [Vaz] (2013).

2. Registros oficiais de criminalidade, através de boletins de ocorrência: Frischtak e Mandel (2012); Cano, Borges e Ribeiro (2012), particularmente em seu Capítulo 6; Ferraz e Ottoni [Vaz] (2013), reproduzido em [Ottoni] Vaz (2014), como Capítulo 1; Sá (2013); Misse (2014); Butelli (2015), particularmente em seu capítulo 1; Magaloni, Franco e Melo (2015); e Pessoa (2016).

3. Índices de vitimizaçáo de caráter não oficial, construídos a partir dos registros do Disque-Denúncia: Ferraz e Ottoni [Vaz] (2013); Monteiro (2013).

O segundo grupo, por sua vez, engloba os estudos concentrados em dimensôes "não criminais", que, por sua vez, permitem algumas inferências sobre as consequências da política de pacificação sobre o gozo de direitos políticos (p. ex., liberdades de associação, de votar e ser votado sem coerção etc.), econômicos (p. ex., direitos ao emprego digno e à livre iniciativa) e sociais (direitos à educaçáo, à saúde, à seguridade social). Os estudos representados no segundo grupo podem ser agrupados, segundo as variáveis dependentes analisadas, em cinco subgrupos:

1. Impactos sobre valores imobiliários: Frischtak e Mandel (2012).

2. Impactos escolares: Butelli (2012), reproduzido em Butelli (2015); Ribeiro (2013).

3. Impactos sobre a renda: Butelli (2015).

4. Impactos sobre acesso a bens e serviços públicos: Butelli (2015).

5. Impactos sobre imigraçáo: Butelli (2015).

6. Impactos eleitorais: [Ottoni] Vaz (2014).

Além dos critérios metodológicos, os estudos analisados se distinguem substancialmente por suas contribuiçôes em relação a três problemas de pesquisa. $\mathrm{O}$ primeiro se refere à delimitação do programa de UPPs e da situação de sua implementação, uma vez que premissas mínimas sobre o programa são necessárias para a composição dos protocolos de avaliação. $\mathrm{O}$ segundo se refere à identificação de critérios explicativos para a escolha das comunidades a serem pacificadas. E, enfim, a questão da mensuração dos possíveis impactos da implantação das UPPs, segundo diferentes recortes categoriais, temporais e espaciais. As próximas seçóes apresentam os resultados da análise dos estudos em relação a cada uma dessas questóes, respectivamente.

\section{O que está em avaliação quando se fala em UPPs?}

Os estudos são consensuais no sentido de apresentarem as UPPs como uma resposta do 
governo fluminense, por um lado, a uma escalada na quantidade e intensidade dos conflitos armados entre grupos ilegalmente armados, tais como quadrilhas de traficantes de drogas e grupos milicianos, e desses grupos contra as polícias estaduais; e, por outro lado, à evidente inefetividade da resposta das polícias a esses conflitos, baseada em aproximaçóes a uma perspectiva de "guerra" contra os traficantes e as favelas nas quais se instalaram, e, no pior dos casos, contra as populaçóes moradoras dessas favelas, levando a um ciclo vicioso de exclusão social, opressão armada e cooptação dos moradores das favelas - particularmente, os jovens homens negros - para as carreiras criminais associadas ao narcotráfico. Cano, Borges e Ribeiro (2012, p. 8) sintetizam essa problemática dos violentos conflitos entre traficantes e policiais nos morros da cidade do Rio de Janeiro:

Ao longo das últimas décadas a cidade do Rio de Janeiro ficou mundialmente conhecida pela dramática contradição entre sua beleza natural e seus elevados níveis de violência. Ao longo dos anos 1980 e 1990 as taxas de homicídio chegaram a valores próximos de 80 vítimas por 100.000 habitantes, entre os piores do país. Para poder processar e vender a droga o varejo do narcotráfico se estruturou a partir do controle territorial das favelas. A feroz disputa pelo território entre diversas facçóes criminosas, e entre elas e a polícia, elevou exponencialmente o número de vítimas e introduziu a necessidade de armas de elevado poder de destruição. A imagem de grupos armados com fuzis controlando as favelas tornou-se corriqueira. A intervençáo do estado estava pautada por um modelo militarizado que contemplava invasōes periódicas dos territórios, que se traduziam numa letalidade policial sem precedentes, mas que náo desarticulavam as estruturas criminosas nem impediam o domínio do território por esses grupos.

Além da disposição belicosa da polícia em relação aos moradores das favelas, outro fator evocado para explicar a ineficácia crônica da política de segurança pública tradicional do Rio de Janeiro é a ampla capacidade do afluente negócio do narcotráfico em promover a corrupção policial e política, levando à erosão da legitimidade das autoridades municipais e estaduais (FRISCHTAK; MANDEL, 2012, p. 7; BUTELLI, 2012, p. 3-4; MAGALONI; FRANCO; MELO, 2015, p. 9).

Diante desse cenário, Sá (2013) e Magaloni, Franco e Melo (2015) encaram a introdução do programa de UPPs, em 2009, como parte de uma reforma policial mais ampla, implementada pelo governo de Sérgio Cabral (2007-2014), e que incluiria também a introdução do Sistema Integrado de Metas (SIM), uma metodologia de incentivo financeiro para o atingimento de metas em produtividade policial apurada pela redução em três indicadores estratégicos de criminalidade: letalidade violenta ${ }^{13}$, roubos de veículos e roubos de rua (SÁ, 2013, p. 10). Enquanto as UPPs seriam um contraponto às incursóes pontuais e altamente militarizadas das polícias, o SIM faria um contraponto a mecanismos informais e, em alguns casos, formais, de incentivo perverso à brutalidade policial, como a antiga "gratificação por atos de bravura", que, durante sua vigência entre 1995 e 1998, foi um fator promotor do aumento da letalidade nas intervençóes policiais (Magaloni, Franco \& Melo, 2015, p. 13).

A conveniência dessa reforma, porém, não teria ocorrido ao governo Cabral logo de imediato: ainda em 2007, no contexto da realização dos Jogos Pan-Americanos, o governo promoveu uma grande operação de "guerra ao tráfico" no Complexo do Alemão, recebendo críticas durante um evento de alta visibilidade nacional e internacional. A implantação das UPPs poderia ser uma resposta a tal repercussão negativa,

13 Incluídos os chamados "autos de resistência”, ou mortes decorrentes de intervençôes policiais. 
em vista da ambição de sediar novos megaeventos globais (MAGALONI, FRANCO; MELO, 2015, p. 11).

As UPPs não representam uma efetiva ruptura com as invasóes pontuais e militarizadas das favelas pelas polícias, tanto porque esse segue sendo o padrão dominante de atuação policial no Rio de Janeiro, estado e capital (RIBEIRO, 2013, p. 33), quanto porque a ideia de permanência policial nas favelas como uma forma de cabeça de ponte para a oferta de outros serviços públicos e privados já foi explorada no passado, na forma do Centro Integrado de Policiamento Comunitário (Cipoc), implementado nos anos 1980, e do Grupamento de Policiamento em Áreas Especiais (GPAE), no começo dos anos 2000. Sua novidade está, antes, na escala e grau de compromisso com que o policiamento de proximidade foi aplicado, em comparação aos experimentos anteriores, tanto em termos de sua abrangência territorial quanto dos recursos humanos e financeiros comprometidos. Algo, porém, não evidente desde suas primeiras intervençóes: quando da implantação da primeira UPP, em 2008, ainda se remetia ao conceito de Companhia de Policiamento Comunitário (CANO; BORGES; RIBEIRO, 2012, p. 23), e não propriamente a uma Unidade de Polícia Pacificadora, o que indica a falta de planejamento na concepção do programa.

Só com a expansão a partir desse "projeto-piloto" foi possível consolidar a noção de "polícia de pacificação", relacionada a outras duas inovaçóes peculiares às UPPs. A primeira é a diretriz de ampla publicização anteriormente à intervenção tática de uma operação de pacificação. O que Ribeiro (2013, p. 33) denominou "guerra avisada", uma "medida [que] permite que os grupos armados estabelecidos se desmobilizem e abandonem os territórios, o que preserva a segurança dos moradores das comunidades e dos próprios policiais”.
Já Magaloni, Franco e Melo (2015, p. 24-26) evidenciaram como essa publicização da fase de intervençáo tática, intercalada com a fase de estabilização, ambas usualmente conduzidas pelo Batalhão de Operações Especiais (Bope) da PMERJ, induz a diminuição de incidências criminais antes mesmo da instalação propriamente dita de uma UPP. Ao considerarem isso que chamaram sugestivamente de "efeito BOPE" como parte do "tratamento" pelas UPPs, os autores relativizaram a importância da presença permanente do policiamento de proximidade como explicação para mudanças nas incidências criminais.

A segunda inovação, intimamente relacionada à opção da "guerra avisada", diz respeito à desvinculação das UPPs do conceito de "guerra às drogas". Segundo Cano, Borges e Ribeiro (2012, p. 22), ao assumirem tacitamente a continuidade do narcotráfico, os gestores do programa puderam reorientar os esforços da política de segurança para a diminuiçáo dos conflitos e da letalidade, adotando a desestruturação do uso ostensivo das armas de fogo como um dos parâmetros de percepção do sucesso do programa.

\section{Explicando a seleção das comunidades pacificadas}

Quais teriam sido os critérios adotados pela Seseg na escolha das comunidades alvo de intervenção das UPPs? Essa questão é particularmente importante para os estudos que lançaram mão de ferramentas de natureza econométrica (DD e STM), uma vez que a hipótese de não endogeneidade, i.e., que a escolha das comunidades possa ser tomada como aleatória, ou pelo menos não tenha levado em conta as mesmas variáveis de interesse do estudo, é vital para o sucesso desses métodos; quanto maior a semelhança inicial entre os casos analisados, mais difícil é distinguir as mudanças por efeito do "tratamento" 
daquelas que expressam apenas tendências do conjunto. Utilizando tal questão quase como exercício de "calibragem" das ferramentas de avaliação de impacto, a maioria dos estudos é taxativa em descartar as taxas de violência e criminalidade como fatores explicativos para a escolha das comunidades a pacificar, voltando-se, portanto, para a exploração de outras hipóteses explicativas.

Vaz (2014) descarta que a seleção das comunidades tenha beneficiado a base eleitoral do governador Sérgio Cabral. Porém, Pessoa (2016) aponta que, embora as UPPs tenham sido efetivamente instaladas em distritos com baixo desenvolvimento social, elas tinham como vizinhança imediata as áreas com os maiores IDH do estado. Com resultados similares, relativos à renda familiar e idade dos moradores dos bairros onde se encontram as comunidades pacificadas, Butelli (2015) sugeriu que os gestores poderiam estar considerando o poder aquisitivo de eleitorados importantes.

No sentido de estabelecer critérios positivos para a instalação das UPPs, Frischtak e Mandel (2012), bem como Cano, Borges e Ribeiro (2012), sustentaram que o padrão de concentração geográfica das UPPs na Zona Sul e Centro da cidade do Rio de Janeiro formava um evidente cinturão de segurança sobre as áreas que sediariam eventos da Copa Fifa 2014 e das Olimpíadas 2016.

Magaloni, Franco e Melo (2015) sugerem que as autoridades fluminenses teriam escolhido as comunidades que representariam menores riscos táticos e políticos. Por um lado, optando pelas comunidades com menores índices de criminalidade e terreno menos acidentado, protegeriam a política do impacto negativo de uma possível intervenção malsucedida; por outro lado, teriam priorizado o enfrentamento ao grupo criminoso denominado Comando Vermelho (CV), por ser essa facção criminosa mais aguerrida e menos propensa a estratégias de acomodação política, seja pela via do suborno a policiais e políticos (como seria o caso da facção criminosa Amigos dos Amigos - ADA), seja pela via de cooptação direta de (ex-)agentes do Estado e patrocínio a candidaturas próprias (como seria o caso com as milícias).

$\mathrm{Na}$ contramão desses estudos, Monteiro (2013) aponta que dentre as trinta favelas com histórico de mais dias de conflito armado entre 2003 e 2013, conforme apurado por denúncias ao Disque-Denúncia, onze já haviam passado pelo menos pela fase de intervenção tática para pacificação. E que, além disso, características territoriais, como grau de inclinação do morro e distância de vias principais, que tornariam uma favela mais propensa a um maior grau de conflituosidade, coincidiam como fatores explicativos para a instalação de uma UPP.

\section{Impactos criminais das UPPs}

Talvez o impacto mais relevante da política de pacificação segundo os estudos revisados tenha sido a diminuiçáo das mortes violentas ${ }^{14}$ nas comunidades pacificadas. Comparando o comportamento dessa variável como taxa por 100 mil habitantes nas comunidades pacificadas e nos diferentes grupos de controle, Frischtak e Mandel (2012, p. 20) falam de reduçáo "na ordem de $10 \%$ a $25 \%$ para homicídios" ${ }^{15}$; Ferraz e Ottoni (2013, p. 27) falam de "uma diminuição de aproximadamente $59 \%$ no total

14 Categoria que abarca latrocínios, lesôes corporais seguidas de morte, homicídios dolosos e autos de resistência (p.ex., FERRAZ; OTTONI, 2013; p. 13).

15 Tradução do autor. 
de crimes violentos ${ }^{116}$; enquanto Butelli (2015, p. 59) estima uma diminuição "entre $28 \%$ e $36 \%$ " na letalidade violenta. Com base nesses impactos estimados nas taxas de mortes violentas por 100 mil habitantes, Frischtak e Mandel (2012) estimam que as UPPs evitaram pelo menos uma morte por 100 mil habitantes, o que representaria cerca de sessenta pessoas, pelos referenciais de 2011; Cano, Borges e Ribeiro (2012) estimaram um impacto de no mínimo menos cinco mortes mensais ou sessenta mortes anuais; Magaloni, Franco e Melo (2015) estimaram um impacto de menos 1,1 mortes mensais ou treze mortes anuais; Pessoa (2016) estimou que se evitou 15,4 homicídios anuais. Em termos absolutos, Sá (2014) avaliou um impacto de menos 3.507 mortes na capital fluminense, entre 2009 e 2012, como consequência da implantação das UPPs.

Magaloni, Franco e Melo (2015) matizam esses resultados a partir da distinção entre homicídios simples (dolosos e culposos) e as mortes decorrentes de intervenção policial - os chamados autos de resistência -, apontando a diminuiçẫo drástica nesses últimos como principal fator redutor do total das mortes violentas. Os autores estimam o impacto das UPPs como redução de pelo menos 2,4 autos de resistência mensais ou 29 anuais por $100 \mathrm{mil}$ habitantes nas comunidades pacificadas. Ainda segundo os autores, esse resultado teria menos a ver com a implantaçáo de uma UPP e as virtudes do policiamento de proximidade, do que com aquilo que denominaram "efeito BOPE": os autores argumentaram que a redução unilateral da letalidade das polícias, associada a uma clara demonstraçáo de superioridade bélica, implicaria na diminuição dos níveis de letalidade antes da instalação de uma UPP propriamente dita, e mesmo meses antes das intervençóes táticas, indicando um tipo de "efeito de antecipação" ${ }^{17}$ (Ibid., p. 25) para outras favelas passíveis de "tratamento".

A queda nos índices de mortes violentas foi acompanhada de crescimento no número de registros de quase todas as demais tipificaçôes criminais. Isso indicaria, por um lado, o incremento real dos crimes, em vista da eliminação de certo grau de controle social autoritário até então exercido pelos "donos dos morros", intolerantes a determinados crimes, como estupros (CANO; BORGES; RIBEIRO, 2012; FERRAZ; OTTONI, 2013; BUTELLI, 2015; MAGALONI; FRANCO; MELO, 2015). A diminuição dos roubos nas vizinhanças das comunidades foi apontada como uma forma de corroboração dessa constatação, pois seriam anteriormente facilitados pelo aluguel de armas de fogo ociosas, promovido pelas facçôes criminosas (FERRAZ; OTTONI, 2013, p. 3).

Por outro lado, esse crescimento poderia indicar apenas a superação da subnotificação, uma vez que a presença policial aumentaria sobremaneira as oportunidades para registros de crimes antes ignorados pelo Estado ou "processados" pelo sistema paralelo de puniçóes dos grupos armados. Nesse sentido, Monteiro (2013) apontou que, desde 2010, o Disque-Denúncia passou a receber denúncias de conflitos armados nas favelas em quantidade superior ao do número de conflitos individuais identificados em mais de uma dessas denúncias.

Ferraz e Ottoni (2013) argumentam que o aumento tanto dos registros criminais oficiais quanto das denúncias extraoficiais (DisqueDenúncia) de abusos de autoridade policial poderia indicar um fortalecimento da confiança da população nas instituiçôes. Porém, considerando a persistência desses registros, conjugada

16 I.e., mortes violentas. Vide nota 13.

17 Tradução do autor. 
ao retorno dos casos de ataques a policiais e de pressóes no sentido de aumento dos autos de resistência a partir de 2013, tais dados sugerem a deterioração da política de pacificação a começar pelos seus principais resultados. Não obstante, os níveis de conflitos armados (MONTEIRO, 2013) e de mortes violentas (MAGALONI; FRANCO; MELO, 2015) ainda se mantinham estáveis em níveis baixos em meados de 2013.

Sá (2013) e Misse (2014) sugerem que se considere a sinergia entre a instalaçáo das UPPs e os incentivos do Sistema Integrado de Metas (SIM), uma vez que este visa monitorar e premiar resultados em diminuição de letalidade violenta, roubos a veículos e roubos de rua, o que poderia influenciar a produção policial dos registros criminais nas comunidades pacificadas e arredores. Sobre a possibilidade de deterioração da pacificação, Misse (Ibid.) sugere o quadro mais preocupante, ao apontar para a plausibilidade de que policiais tenham sistematicamente adulterado os registros de mortes violentas, passando a registrá-las como desaparecimentos, que de fato apresentaram tendência de aumento nas comunidades pacificadas. $\mathrm{O}$ caso do ajudante de pedreiro Amarildo ${ }^{18}$ é apenas o mais notório exemplo dessa possibilidade.

\section{Impactos sociais das UPPs}

A presença das UPPs parece ter impactos diferenciados sobre dimensóes relevantes para outras políticas públicas fora do escopo da segurança pública, e que podem ser interpretadas a partir da chamada "agenda social" para os territórios pacificados. Frischtak e Mandel (2012) demonstraram que as UPPs tiveram impacto de cerca de $15 \%$ na valorização do mercado imobiliário formal na cidade do Rio de Janeiro, com valorização desproporcionalmente maior em imóveis mais baratos nos bairros com comunidades pacificadas, indicando que quase metade da diminuição da desigualdade patrimonial entre bairros da cidade entre 2008 e 2011 poderia ser atribuída às UPPs. Traduzindo em termos de coeficiente de Gini, a diminuição entre 2,5 e 5 pontos faria a política de pacificação comparável às políticas explicitamente orientadas para a diminuição da desigualdade, como o Programa Bolsa Família (Ibid., p. 27).

Butelli $(2012$; 2015) demonstrou impactos positivos, mesmo que tímidos, das UPPs no desempenho escolar de adolescentes que, se estivessem fora da escola, estariam em idade ideal para aliciamento pelo tráfico, isto é, a partir dos 13 anos. Ribeiro (2013) apresenta uma hipótese de mecanismo explicativo para esse tipo de resultado, através da constatação dos efeitos positivos da instalação de UPPs na mobilidade docente em escolas municipais, particularmente no ingresso de novos professores, possivelmente mais motivados.

Em relação ao bem-estar e qualidade de vida, as comunidades pacificadas teriam se tornado mais atrativas para imigrantes (BUTELLI, 2015). Quanto ao acesso a ativos domiciliares (computadores, automóveis e casa própria), assim como a serviços públicos de água, esgoto e coleta de lixo dentro das comunidades pacificadas, a política parece ter apresentado resultados pouco consideráveis (Id.). Ao que parece, ela também não acarretou em maior empregabilidade e, portanto, maior renda do trabalho. Em vez disso, os incrementos diferenciais de renda observados em comunidades pacificadas estariam relacionados antes ao aumento do acesso a benefícios sociais. Em relação a esse incremento de renda, um aspecto importante apontado no estudo de caso de Butelli (Id.) sobre a Cidade de Deus foi que os principais beneficiários já ocupavam os mais altos percentis de renda dentro da comunidade antes da pacificação. 
No que se refere ao exercício de direitos políticos, Vaz (2014) aponta que, na mesma medida em que é possível demonstrar que a escolha das comunidades a pacificar não beneficiou as bases eleitorais do governador Sérgio Cabral, eleito em 2006, a política de pacificação teria redundado em recompensas eleitorais consideráveis para esse mandatário, tendo em conta a contribuição das zonas eleitorais próximas de UPPs para a sua reeleição em 2010, e para a reeleiçáo de seu apadrinhado político, Eduardo Paes, para o cargo de prefeito, em 2012. O menor nível de recompensa para esse último levou Vaz (Id.) a concluir que as populaçôes das comunidades pacificadas reconhecem a política de pacificação como mérito do governador responsável pela sua implementação, sinalizando apoio eleitoral à continuidade da política.

\section{Sínteses, lacunas e desafios na avaliação das UPPs}

Os estudos de avaliação de impacto do programa de UPPs representam uma inegável contribuição para a compreensão dos sentidos da política de pacificação do Rio de Janeiro. Em primeiro lugar, o rigor com que elaboraram sobre as consequências hipotéticas e, principalmente, empiricamente observadas sobre as UPPs confere a esse conjunto de literatura um alto refinamento descritivo, que dificilmente seria obtido pela simples leitura das normas e discursos oficiais acerca da política de pacificação. Em segundo lugar, ao buscarem explicar os mecanismos por trás dos resultados obtidos, introduziram conceitos e hipóteses úteis para pesquisas ulteriores.

Ainda assim, os estudos foram insuficientes em afastar as ambiguidades sobre a política de pacificaçáo, mesmo no que tange aos resultados do programa de UPPs. A queda abrupta das taxas de letalidade violenta, tomada como resultado da efetividade da política, é imediatamente matizada pelo fato de ter como principal fator explicativo a diminuição da letalidade da própria polícia. O próprio aumento da notificação de outros crimes em paralelo ao aumento de denúncias de abusos dos próprios policiais, por sua vez, pode apontar para um aumento da segurança e confiança dos moradores das favelas em acionarem as autoridades públicas. Se a principal entrega para as comunidades pacificadas parece ter sido uma polícia em si "pacificada", qual a importância da desarticulação dos grupos armados ilegais na garantia da paz e do desenvolvimento social e econômico das comunidades pacificadas (assumindo-se que esses objetivos anunciados na formulação do programa foram, de fato, perseguidos)?

Os estudos também não identificaram impactos sociais e econômicos que apontem para uma diminuição das desigualdades entre "morro" e "asfalto". Mesmo o mais significativo desses resultados, a diminuição de até cinco pontos do índice de Gini de preços residenciais, apontado por Frischtak e Mandel (2012), diz respeito antes a externalidades positivas para os bairros vicinais às comunidades pacificadas. $\mathrm{O}$ principal efeito da pacificação no sentido de superação do estigma do Rio de Janeiro como "cidade partida" pela desigualdade pode ter sido a "homogeneização" desta, isto é, ter promovido o aumento da desigualdade dentro das comunidades pacificadas, emulando o padrão excludente observado na comparação entre essas e o restante da cidade (BUTELLI, 2015).

Por outro lado, para além da mera quantificação dos impactos socioeconômicos da implantação das UPPs, os estudos revisados apontaram, como alternativa de investigação a partir de técnicas quantitativas, a avaliação de como fatores endógenos e exógenos afetaram as decisóes de implementação do programa, sendo os testes sobre os fatores explicativos da escolha dos locais de intervençáo os principais exemplos nesse sentido. 
$\mathrm{Na}$ medida em que se acumulam sinais de iminência da descontinuidade da política de pacificação diante da grave crise fiscal e de legitimidade que se abate sobre o Governo Estadual do Rio de Janeiro, uma agenda de pesquisas segundo essa orientação poderia se debruçar sobre questóes como: qual a influência da capacidade fiscal, bem como de outras capacidades estatais, nas escolhas pela implantação, expansão e estagnação do programa de UPPs? Há relação entre as poucas evidências de efetividade do "braço social" da pacificação e a estratégia adotada para a expansão de seu "braço policial"? Essa estratégia, baseada na lotação simultânea de várias UPPs, tornou o programa mais vulnerável ao presente choque fiscal? Como a performance das UPPs pode ter sido afetada pela normatização de 2011, bem como pela entrada de outros atores além das polícias estaduais nas intervençóes nas comunidades? Enfim, é possível identificar, quantitativamente, quais outros fatores endógenos e exógenos contribuíram para o desgaste e estagnação da política de pacificação?

\section{Referências}

BOTELHO, L. L. R.; CUNHA, C. C. A.; MACEDO, M. O método da revisão sistemática integrativa nos estudos organizacionais. Gestão \& Sociedade, Belo Horizonte, v. 5, n. 11, p. 121-136, 2011.

BUTELLI, P. H. O impacto das UPPs sobre a performance escolar no Rio de Janeiro. 2013. 43 f. Dissertação (Mestrado em Economia) - Fundaçáo Getúlio Vargas, Rio de Janeiro, 2012.

Avaliação de impacto de políticas de segurança: o caso das unidades de polícia pacificadora no Rio de Janeiro. 2015. 191 f. Tese (Doutorado) - Fundação Getúlio Vargas, Rio de Janeiro, 2015.

CANO, I.; BORGES, D.; RIBEIRO, E. (Orgs.). Os donos do morro: uma avaliaçâao exploratória do impacto das Unidades de Polícia Pacificadora (UPPs) no Rio de Janeiro. Rio de Janeiro: LAV;Uerj, 2012.

CASO Amarildo: Justiça confirma que PMs torturaram e mataram a vítima. O Dia, Rio de Janeiro, 1 fev. 2016.

COHEN, E.; FRANCO, R. Avaliação de projetos sociais. 8. ed. Petrópolis: Vozes, 2008.

DE-LA-TORRE-UGARTE-GUANILO, M. C.; TAKAHASHI, R. F.; BERTOLOZZI, M. R. Revisão sistemática: noções gerais. Revista da Escola de Enfermagem da USP, São Paulo, v. 5, n. 45, p. 1260-1266, 2011.

FARIA, C. A. P. A política da avaliação de políticas públicas. Revista Brasileira de Ciências Sociais, São Paulo, v. 20, n. 59, p. 97-169, 2005.

FERRAZ, C.; OTTONI, B. Os efeitos da pacificação sobre o crime e a violência. Fucape, Rio de Janeiro, 2013. Disponível em: <https://bit.ly/2KwIUW0>. Acesso em: 26 out. 2017.

FERREIRA, N. S. A. As pesquisas denominadas estado da arte”. Educação \& Sociedade, Campinas, ano 23, n. 79, 2002, p. 257-272, 2002. 
FGV PROJETOS. Segurança pública em foco. Rio de Janeiro: Editora FGV, 2012.

FILOCRE, D. Classificação de políticas de segurança pública. Revista Brasileira de Segurança Pública, São Paulo, v. 3, n. 5, p. 146-158, 2009.

FRISCHTAK, C.; MANDEL, B. R. Crime, house, and inequality: the effect of UPPs in Rio. Federal Reserve Bank of New York Staff Reports, New York, 2012. Staff Report 542.

LEITE, M. P. Da metáfora da guerra ao projeto de pacificação: favelas e políticas de segurança públicas no Rio de Janeiro. Revista Brasileira de Segurança Pública, São Paulo, v. 6, n. 2, p. 374-389, 2012.

LIMA, C. A. Força de pacificação: os 583 dias da pacificação dos complexos da Penha e do Alemão. Rio de Janeiro: Agência 2A Comunicação, 2012.

MAGALONI, B.; FRANCO, E.; MELO, V. Killing in the slums: an impact evaluation of police reform in Rio de Janeiro. Stanford Center for International Development, Palo Alto, 2015. Working Paper 556.

MISSE, D. G. Cinco anos de UPP: um breve balanço. Dilemas, v. 7, n. 3, p. 675-700, 2014.

Os programas de gestão social em territórios pacificados. Confluências, v. 15, n. 1, p. 11-22, 2013.

MONTEIRO, J. Os efeitos da política de pacificação sobre os confrontos entre facçôes de drogas no Rio de Janeiro. Rio de Janeiro: FGV; IBRE, 2013.

PESSOA, M. S. 2016Segurança pública no Rio de Janeiro: um estudo dos homicídios dolosos entre 2003 e 2014 . Ipea, Rio de Janeiro, 2014. Texto para Discussão 2204.

RIBEIRO, E. Impactos educacionais das Unidades de Polícia Pacificadora: explorando efeitos sobre fluxo docente. Intratextos, v. 4, n. 1, p. 27-52, 2013.

RIPLEY, R. B. Stages of the policy process. In: Policy analysis in political science. Chicago: Nelson-Hall, 1985. p. 48-55.

RIO DE JANEIRO, Governo do Estado (2009). Decreto no 41.650, de 21 de janeiro de 2009. Dispóe sobre a criação da unidade de polícia pacificadora - UPP e dá outras providências. Diário Oficial do Estado do Rio de Janeiro. Poder Executivo. Rio de Janeiro, RJ, Ano XXXIV, no 012, 22 de dez. de 2009, Parte I, p. 4.

RIO DE JANEIRO, Governo do Estado (2011). Decreto no 42.787, de 06 de janeiro de 2011. Dispóe sobre a implantação, estrutura, atuação e funcionamento das Unidades de Polícia Pacificadora (UPP) no Estado do Rio de Janeiro e dá outras providências. Diário Oficial do Estado do Rio de Janeiro. Poder Executivo. Rio de Janeiro, RJ, Ano XXXVII, n. 005, 7 de jan. de 2011, Parte I, p. 2-3.

SÁ, A. R. C. Sistema Integrado de Metas e acompanhamento de resultados da Secretaria de Estado de Segurança do Rio de Janeiro. In: VI CONGRESSO CONSAD DE GESTÁO PÚBLICA, 6., 2013, Brasília, DF. Anais... Brasília, DF: Consad, 2013. p. 1-29. 
VAZ, B. O. E. Três ensaios em microeconometria sobre crime, política e migração. 2014. 140 f. Tese (Doutorado) - Pontifícia Universidade Católica, Rio de Janeiro, 2014.

ZALUAR, A.; ALVITO, M. (Orgs). Um século de favela. 5. Ed. Rio de Janeiro: Editora FGV, 2006.

\section{Resumo}

O que dizem as avaliaçóes de impacto das Unidades de Polícia Pacificadora (UPPS)?

A avaliaçăo de impacto das Unidades de Polícia Pacificadora (UPPs) se apresenta como uma estratégia pragmática para a superaçáo das ambiguidades ainda presentes na política de pacificação do Governo Estadual do Rio de Janeiro. A partir da revisão sistemática do estado da arte da avaliação de impacto das UPPs, o presente paper identificou a diminuição da letalidade policial como principal impacto das UPPs em variáveis criminais, e a insuficiência de resultados indicativos de sua efetividade na melhoria de aspectos sociais das comunidades pacificadas. $\mathrm{O}$ paper inova ao propor uma abordagem indireta e qualitativa dos dados quantitativos sobre as UPPs e seus efeitos sociais, mobilizando o conhecimento acumulado em uma área de fronteira nos estudos sobre a política de pacificaçâo do Rio de Janeiro, bem como ao sistematizar os pressupostos metodológicos e conceituais e sumarizar as principais questôes de investigação, resultados e descobertas de tais estudos.

Palavras-chave: Unidades de Polícia Pacificadora (UPPs); Avaliação de Impacto; Revisão Sistemática; Políticas Públicas (Subnacionais); Rio de Janeiro.

\section{Abstract}

\section{What do impact evaluations of the Pacifying Police Units (UPPs) say?}

The impact evaluation of the Pacifying Police Units, or UPPs, presents itself as a pragmatic strategy to overcome the still present ambiguities about the pacification policy of Rio de Janeiro state government. Through the systematic review of the state-of-the-art on impact evaluation of the UPPs, the present paper identified the diminish on police killing as the principal impact of the UPPs on criminal variables, and insufficiency of results indicating its effectiveness in bettering social aspects of the pacified communities. The paper innovates in proposing an indirect, qualitative approach to the quantitative data on the UPPs and their social effects, mobilizing the accumulated knowledge on a frontier field of research on Rio de Janeiro's pacification policy. As well as by systematizing the methodological and conceptual assumptions, and summarizing the principal questions of inquire, results and findings of such studies.

Keywords: Pacifying Police Units (UPPs); Impact Evaluation; Systematic Review; Public Policies (Subnational); Rio de Janeiro.

\section{Résumé}

\section{Que disent les évaluations de l'impact des Unités de Police Pacificatrice (UPPS)?}

L'évaluation de l'impact des Unité de Police Pacificatrice (UPP) se présente comme une stratégie pragmatique pour surmonter les ambiguïtés qui sont encore présentes dans la politique de pacification du gouvernement de l'État de Rio de Janeiro. Basé sur l'examen systématique de l'état de l'art de l'évaluation de l'impact des UPPs, ce papier a identifié la réduction de la létalité de la police comme principal impact des UPPs sur les variables criminelles, et l'absence de résultats indicatives de leur efficacité dans l'amélioration des aspects sociaux des communautés pacifiées. Cet article propose une approche indirecte et qualitative des informations quantitatives sur les UPPs et leurs effets sociaux, en mobilisant le connaissances acquises d'une zone frontalière dans les études sur la politique de pacification de Rio de Janeiro, ainsi que systématiser les hypothèses méthodologiques et conceptuelles, et résumer les principaux questions de recherche, les résultats et découvertes de ces études.

Mots clés: Unités de Police Pacificatrice (UPP) ; Évaluation d'impact ; Révision systématique ; Politiques publiques (sous-nacionaux) ; Rio de Janeiro. 